\title{
Approaching the Loop: A Brief Review of Effective Practises in Continuous Program Improvement
}

\author{
Jake Kaupp and Brian Frank \\ Queen's University \\ kaupp@appsci.queensu.ca
}

\begin{abstract}
Using the results of outcomes based assessment for the purposes of continuous improvement, or closing the loop, is a frequent topic of discussion in higher education, and is becoming more commonplace amongst Canadian engineering programs. There have been several organizations and institutions in the United States that have been investigating outcomes assessment and how institutions use the data for improvement purposes. Most notable of these are the National Institute for Learning Outcomes Assessment and the schools participating the in the Wabash Study. Despite these investigations and discussions, there is no clear consensus of what a functioning closed loop resembles, due to the diversity that exists between one institution and the next. Ultimately it will be the decision of an individual institution as to what the final process will resemble, but there are some key or effective practises for continuous improvement that can help institutions guide and shape their approach to closing the loop.
\end{abstract}

This paper will briefly review the current landscape in continuous improvement in higher education, and present effective practises, common themes and techniques for closing the loop. The intent of this paper is to provide a resource collection of effective practises to help develop a meaningful, sustainable and practical data-informed continuous improvement process with a focus on engineering.

Keywords: Continuous Improvement, Closing the Loop, Outcomes assessment, Wabash study, Effective practise

\section{INTRODUCTION}

The landscape of engineering education has changed, first with the introduction of the Washington Accord[1]requiring member countries to adopt outcomesbased education, and second with the Canadian Engineering Accreditation Board (CEAB) adopting an outcomes-based, data-informed continuous curriculum improvement accreditation mandate using graduate attributes (GA) [2]. While outcomes-based practises have existed prior to both of these initiatives, the awareness and application of them slowly crept into consciousness of engineering educators bringing with it a new way of talking about education and assessment. Indicators, outcomes, rubrics, triangulation and Bloom's taxonomy are frequently discussed topics, as evidenced by the growing collection of publications and attendees at the Canadian Engineering Education Association (CEEA) Annual Meetings. Since 2012, the engineering education community has become comfortable with many aspects of the outcomes-based mandate, yet the continuous curriculum or program improvement side of the mandate is an area of much concern and question.

More commonly referred to as "closing the loop", using the results from the assessment of student learning outcomes for the improvement purposes appears on the surface to be a straightforward exercise. Simply collecting the data of student performance and improving a single course on its own may be straightforward, but making meaning of the data and then effectively implementing a change across a program is far more complex. It requires a depth of understanding, considerable insight, knowledge of student development, a clear picture how students learn, effective teaching practises, a firm grasp of assessment, and most importantly, time.

There are very few institutions, maybe none, who can say that they have a fully functional institution- wide continuous improvement process and strong evidence of improved learning, yet there is much research conducted in this area. The most notable are the Wabash National Study of Liberal Arts Education, a longitudinal, large scale study to investigate critical factors that affect the outcomes of liberal arts education, and from the National Institute for Learning Outcomes Assessment (NILOA) an organization of prominent assessment scholars and experts. Using these studies and publications as a base, alongside continuous improvement and accountability practises from other professional disciplines, common themes, effective practises and key lessons regarding using assessment results to improve your program can be found. 


\section{Accountability, Professional Programs \& Approaches}

There are a diverse number of techniques and approaches associated with continuous improvement. The majority of these techniques, along with closing the loop, are related to accountability, which holds institutions responsible for improving student performance[3], [4]. The topic of accountability in higher education is prominent in the United States and is inexorably linked to assessment.

It can be split into two areas; the first is assessment for accountability, using assessment results to hold an institution accountable for student performance and is typically associated with external agencies, government and accreditation bodies and standardized testing initiatives[5]. The second is assessment for improving student learning, best put by Blaich as:

"Accountability for improving student
learning as an enactment of the moral and
professional commitments of faculty, staff,
and institutions, rather than as a reaction to
externally imposed obligations. is an idea
that rarely surfaces in the public discussion
about assessment and accountability[6]"

This viewpoint is shared by assessment professionals and higher education researchers[7], and alongside external factors (accreditation) is a significant internal factor behind implementing outcomes-based, continuous improvement process by honouring professional commitments as educators and truly improving student learning.

Through being accountable for improving student learning, an institution can be accountable to all stakeholders by demonstrating enhanced student learning across both professional and non-professional programs[7], [8]. It is important for an improvement process to consider both facets of accountability, to clearly define what they are trying to assess and improve and to ensure whatever approach they employ can address external and learning accountabilities.

Alongside engineering, the common professional programs at institutions are business and medicine, both of which have multiple accrediting bodies and standards. The requirements for accreditation across all of these programs share common aspects: a learning outcomes focus and the demonstration continuous improvement. Despite these similarities, there are a number of approaches used to address or implement a continuous improvement process or to close the loop. They are not solely used in the professionally accredited programs, but are also found across higher education with those seeking to answer questions about accountability and student learning[9].

Derived from the pioneering work of W. Edwards Deming[10] in continuous improvement and used by industry to improve quality and effectiveness, several approaches have been modified for use in higher education and have shown some promise. These include: Deming's original plan-do-check-act (PCDA) cycle used in engineering in the SUCEED coalition[11], lean manufacturing and six sigma methodologies[10], [12], total quality management (TQM) or total quality improvement (TQI) applied broadly to higher education[13]-[15], the balanced scorecard approach in accounting programs[16] and other quality improvement practises in nursing[17], [18] and medicine[19].

\section{Effective Practise \& Common Challenges}

The Wabash Study has been an invaluable resource for those interested in implementing outcomes-based assessment practises. This study has helped build momentum to make student learning outcomes a primary assessment method of an institution and further the accountability assessment to improve student learning. Even with the success of the study, several questions were unanswered, as stated by Blaich \& Wise in their 2011 analysis of the study:

"Despite the abundant information they receive from the study, most Wabash Study institutions have had difficulty identifying and implementing changes in response to study data. Although much of the national conversation about assessment and accountability focuses on the pros and cons of different approaches to measuring student learning and experience, we have learned from the Wabash Study that measuring student learning and experience is by far the easiest step in the assessment process. The real challenge begins once faculty, staff, administrators, and students at institutions try to use the evidence to improve student learning." [6]

Even though this key question of 'how to close the loop' largely remains unanswered, the results from the Wabash study alongside the many varied approaches to continuous improvement in higher education can be used to identify effective practises and common challenges. It should be noted that not all of the practises and techniques are required to form an effective continuous improvement process, nor would an institution experience all of the challenges. Rather, these practises should be viewed guide in developing an improvement process that uses assessment of student learning outcomes to inform 
decisions, improve courses and curriculum, and provide a meaningful contribution to furthering student learning.

\subsection{Effective Practise}

\subsubsection{Have a key goal or focus to guide your approach}

Any successful outcomes-based continuous improvement process requires direction. An aimless or undirected process is rarely successful or sustainable over the long term, due to lack of focus, a lack of alignment and a lack of engagement. Beginning the process by asking questions to discern key goals, purpose or a specific focus will help clarify what exactly is to be gained by undertaking the process. Having these key questions, goals and purpose will assist with engagement with stakeholders by establishing transparency and intent of the process[20]. This is especially important in professional programs with accreditation mandates, as an external mandate or pressure won't facilitate engagement[8] if these mandate don't accurately align with the purposes and goals of an institution or program[20]. Carefully fostering alignment between institution, program and disciplinary goals and values is important for building stakeholder engagement and developing enduring support and 'buy-in' for a continuous improvement approach[21]. This can be facilitated by an institutional or program framing of the improvement process, by carefully embedding the process in program review or in governance structures[20].

\subsubsection{Resource identification \& allocation}

Don't reinvent the wheel. There may already exist a meaningful amount of information previously collected about student learning at your institution, collected by a variety of sources. It is very important to perform a thorough audit of this information to form benchmark measures, and to better shape goals, objectives, and methodologies[6], [20]. Additionally, an audit and allocation of current resources should be conducted to provide a resource with the capital it requires to build momentum and progress towards long-term sustainability[21]. Resource allocation should also include a forecast for future efforts, which should include the collection of stakeholder opinions for the assessment of the approach itself and the assessment results collected thus far[6], [8].

\subsubsection{Leadership}

Effective, continuous and invested leadership is vital for the implementation and long-term sustainability of an approach. While by-committee approaches are popular, clear direction and guidance is required due to the turnover rates associated with such governance[8]. At the core, embarking on an outcomes-based continuous improvement approach is an exercise in change management, and the absence of an engaging and effective leader will pose significant problems. However, the presence of internal "champions" and "pockets of excellence" in outcomes-based assessment can provide ad-hoc leadership to help supplement a transitional leader or a committee based approach[20]. These champions typically are the early-adopters, effective educators and highly involved faculty or staff members. Identifying and involving these people in an improvement approach is vital for the efficacy, short-term survivability and longterm sustainability of an approach.

\subsubsection{Clear \& Coherent Assessment Plan}

The crafting of a clear and coherent assessment plan is an effective practise for a number of reasons that goes beyond the simple mapping of the curriculum, or addressing accreditation. Developing a clear assessment and improvement plan will help establish expectations for an institution or program and communicate those expectations to stakeholders[8], involving them in the process and helping build a sense of ownership, engagement and a sense of community at an institution or program[21], [22]. Embarking on such efforts will also help enhance assessment and improvement practises already in place and better use, interpret and leverage the data collected by said processes[20]. The continual nature of the approach should be addressed, with assessment and evaluation of the approach considered in the planning steps[20]. Establishing a scope of work as part of an assessment plan is of vital importance to not overreach and tax available resources. A deliberate, scalable approach limiting improvements to a small number of areas is a sensible approach that can be modified and expanded once sufficient momentum is gained[20].

Most importantly, an assessment plan should include efficient and effective pathways for communication between all stakeholders involved in the process. Without transparency and communication of the plan, stakeholders will not have an accurate picture on which to base decisions, and raise concerns about the validity and efficacy of curriculum or program improvements[8]. 


\subsubsection{Making Meaning \& Improving}

Collecting assessment data has been shown to be the easiest part of an outcomes-based continuous improvement process[20]. Making meaning from the assessment results, distilling that into a set of actionable improvements and then implementing those improvements should be unequivocally easier said than done. Making meaning of your data is a question of space and a matter of time; in order to properly understand the vast amount of information gained from assessment processes significant time must be allocated for reflection and in a common space for collective and collaborative decision making[20]. Unrealistic timelines for change, and exclusive discussion not involving representatives from all stakeholders are detriments to an improvement approach[8], and an ill-informed, hastily reached decision may be far more damaging than doing nothing.

The data gained from the assessment process should be communicated widely and freely, to all stakeholders, and their input on how to interpret meaning and suggestions for improvement is considered. This will help foster engagement in and understanding for the approach to continuous improvement in a program or institutions and develop a culture around assessment and improvement[21], [22]. Engaging all stakeholders also helps to establish internal accountability of the process, by considering diverse and conflicting viewpoints to achieve unbiased, actionable recommendations for improvement[8]. Diverse stakeholder input is an additional benefit when one considers the context and nuance of the data. Deriving meaning from seemingly spurious or clouded data may be made clear by a specific group of stakeholders with a particular level of insight[21].

Just as student learning is being assessed and improved by closing the loop, the approach used by an institution should also be evaluated and improved[8]. Embarking on an outcomes-based continuous improvement process is a learning experience. There will be successes, challenges, victories and failures throughout the process as the approach to measure and demonstratively improve student learning matures. As any student should, institutions should plan to self-assess their own efforts, and not just mindlessly collect data to meet accountability and accreditation requirements. High volume of data does not necessarily equate with high quality of data and imply a successful process or the improvement of student learning[21]. As best put by Trudy Banta:

"One of the challenges of translating assessment evidence into improvement is for assessment leaders to know when gathering more information would help focus and clarify potential actions and when their knowledge is good enough to change a class or program. The goal of assessment is not just to gather evidence, after all, but to make evidence-informed changes." [8]

\section{Conclusions}

The categories of effective practice presented above represent lessons learned from the successes and challenges of institutions undertaking their own continuous improvement process.

These are not "best practises" that every institution should follow, but instead should be viewed as "effective practises" gathered from shared institutional experiences and the reflections of assessment professionals on the challenges of closing the loop.

Many of the tenets of effective practice in the outlined are very well aligned with the EGAD 5-step approach to outcomes based curriculum development. The EGAD framework was developed in collaboration with assessment professionals and drew from successful evidence-based practise in outcomes assessment. Each step in the EGAD process provides key questions to guide a developing approach that are representative of the effective practises described in this paper[23] [24].

1. Program Evaluation

a. What are the unique aspects of your program?

b. What is the purpose of your program?

c. What are the outcomes of your program?

2. Curriculum Mapping

a. Where are the outcomes developed in your program?

b. Where are the outcomes assessed in your program?

c. What mapping technique best suits your programs needs?

3. Assessment \& Data Collection

a. How are you going to measure learning in specific outcomes?

b. Are you triangulating measures of student learning?

c. What is your plan to assess learning outcomes?

4. Analyzing \& Interpreting Data

a. What do you want to know to improve your program?

b. How are you going to manage outcomes assessment data?

c. How will you present your data?

5. Data Informed Curriculum Improvement

a. What is your purpose for the current improvement cycle

b. What criteria might you chose to judge the success of changes made 
Whether a continuous improvement approach follows effective practises, a developmental ideology or established framework, there is a common goal driving the process:

"the desire to improve student learning and to critically examine institutional processes and practices-from the classroom to extracurricular activities and everything in between-to inform decisions to enhance student learning." [20]

\section{Acknowledgements}

The authors would like to acknowledge support from the DuPont Canada Chair in Engineering Education Research and Development. Support for the EGAD initiative was provided by Engineers Canada and the National Council of Deans of Engineering and Applied Science.

\section{References}

[1] "IEA Graduate Attributes and Professional Competency Profiles," washingtonaccord.org. [Online]. Available:

http://www.washingtonaccord.org/IEA-GradAttr-Prof-Competencies-v2.pdf. [Accessed: 16Sep-2013].

[2] Canadian Engineering Accreditation Board, "Accreditation Criteria and Procedures," Engineers Canada, Ottawa, ON, 2012.

[3] R. J. Shavelson, "Assessing student learning responsibly: From history to an audacious proposal," Change: The Magazine of Higher Learning, vol. 39, no. 1, pp. 26-33, 2007.

[4] P. T. Ewell, "Assessment and accountability in America today: Background and context," New Directions for Institutional Research, vol. 2008, no. 1, pp. 7-17, 2008.

[5] J. Huisman and J. Currie, "Accountability in higher education: Bridge over troubled water?," High Educ, 2004.

[6] C. F. Blaich and K. Wise, "From Gathering to Using Assessment Results," National Institute for Learning Outcomes Assessment, 2011.

[7] T. W. Banta, "Can assessment for accountability complement assessment for improvement," Peer Review, 2007.

[8] T. W. Banta and C. F. Blaich, "Closing the Assessment Loop," Change: The Magazine of Higher Learning, vol. 43, no. 1, pp. 22-27, Dec. 2010.

[9] D. M. Thalner, "The practice of continuous improvement in higher education," 2005.

[10] N. Bhuiyan and A. Baghel, "An overview of continuous improvement: from the past to the present," Management Decision, 2005.

[11] C. E. Brawner, T. J. Anderson, C. F. Zorowski, R. C. Serow, and J. Demery, "Closing the loop: Using qualitative assessment in the continuous quality improvement of the SUCCEED Coalition," vol. 3431, 1999.

[12] J. Antony, N. Krishan, and D. Cullen, "Lean Six Sigma for higher education institutions (HEIs): Challenges, barriers, success factors, tools/techniques," International Journal of ..., 2012.

[13] R. G. Lewis and D. H. Smith, "Total Quality in Higher Education. Total Quality Series.," 1994.

[14] W. L. Hansen and W. L. Hansen, "Bringing Total Quality Improvement into the college classroom," High Educ, vol. 25, no. 3, pp. 259279, Apr. 1993.

[15] R. V. Hogg and M. C. Hogg, "Continuous quality improvement in higher education," International Statistical Review/Revue Internationale de Statistique, pp. 35-48, 1995.

[16] O. H. Chang and C. W. Chow, "The balanced scorecard: A potential tool for supporting change and continuous improvement in accounting education," Issues in Accounting Education, vol. 14, no. 3, pp. 395-412, 1999.

[17] J. F. Brown and B. L. Marshall, "Continuous quality improvement: An effective strategy for improvement of program outcomes in a higher education setting," Nursing Education Perspectives, vol. 29, no. 4, pp. 205-211, 2008.

[18] V. S. Carroll, G. Thomas, and D. DeWolff, "Academic Quality Improvement Program: Using Quality Improvement as Tool for the Accreditation of Nursing Education," Quality Management in Healthcare, vol. 15, no. 4, p. 291, 2006.

[19] B. E. Gould, "Adding continuous quality improvement to a medical school curriculum: problems and possibilities.," Virtual Mentor, vol. 6 , no. 6, 2004.

[20] G. R. Baker, N. A. Jankowski, S. Provezis, and J. Kinzie, "Using Assessment Results: Promising Practices of Institutions That Do It Well," National Institute for Learning Outcomes Assessment, 2012.

[21] T. E. Reed, J. Levin, and G. H. Malandra, "Closing the Assessment Loop by Design," Change: The Magazine of Higher Learning, vol. 43, no. 5, pp. 44-52, Aug. 2011.

[22] C. A. Dwyer, C. M. Millett, and D. G. Payne, "A Culture of Evidence: Postsecondary Assessment and Learning Outcomes. 
Recommendations to Policymakers and the Higher Education Community.," Educational Testing Service, p. 35, 2006.

[23] B. Frank, S. Fostaty-Young, S. McCahan, P. Wolf, P. Ostafichuck, K. C. Watts, and N.

Saleh, "Engineering graduate attribute development (EGAD) project," presented at the Proceedings of the Canadian Engineering Education Association, St. John's, NFLD, 2011.

[24] EGAD Project, "A 5 Step Guide To Curriculum Development | EGAD Project," 2011. [Online]. Available: http://egad.engineering.queensu.ca/?page_id $=85$ 7. [Accessed: 14-Apr-2014]. 